QUALITY IMPROVEMENT REPORT

\title{
Reducing inequalities in access to health care: developing a toolkit through action research
}

\author{
E C Goyder, L Blank, E Ellis, A Furber, J Peters, K Sartain, C Massey
}

Qual Saf Health Care 2005;14:336-339. doi: 10.1136/qshc.2005.013821

See end of article for authors' affiliations

Correspondence to:

Dr E C Goyder, ScHARR, University of Sheffield, Sheffield S1 4DA, UK' e.goyder@sheffield.ac.uk

Accepted for publication 26 June 2005
Problem: Healthcare organisations are expected both to monitor inequalities in access to health services and also to act to improve access and increase equity in service provision.

Design: Locally developed action research projects with an explicit objective of reducing inequalities in access. Setting: Eight different health care services in the Yorkshire and Humber region, including community based palliative care, general practice asthma care, hospital based cardiology clinics, and termination of pregnancy services.

Key measures for improvement: Changes in service provision, increasing attendance rates in targeted groups.

Strategies for change: Local teams identified the population concerned and appropriate interventions using both published and grey literature. Where change to service provision was achieved, local data were collected to monitor the impact of service change.

Effects of change: A number of evidence based changes to service provision were proposed and implemented with variable success. Service uptake increased in some of the targeted populations.

Lessons learnt: Interventions to improve access must be sensitive to local settings and need both practical and managerial support to succeed. It is particularly difficult to improve access effectively if services are already struggling to meet current demand. Key elements for successful interventions included effective local leadership, identification of an intervention which is both evidence based and locally practicable, and identification of additional resources to support increased activity. A "toolkit" has been developed to support the identification and implementation of appropriate changes.
$\mathrm{T}$ he requirement that UK healthcare organisations produce equity audits has highlighted the persistence of the "inverse care law"1 $^{\prime \prime}$ in many areas of health care. However, equity audit requires healthcare commissioners and providers to do more than just evaluate whether access to services is equitable. It also requires action to redress identified inequalities in access, particularly where there is evidence that population or patient groups who could most benefit from specific services have lower uptake of those services. $^{2}$ Wherever important inequalities in uptake of services relative to need are identified, service providers need to consider if changes are required to improve access for underserved groups. As with any change to service delivery, there will be a number of obstacles to be overcome and there will be specific problems in encouraging change to improve access to services that are already struggling to meet existing demand.

Recognising these issues and wishing to encourage equity audit, the Regional Public Health Group (Yorkshire and Humber) commissioned an action research project with the aim of developing a number of NHS initiatives to improve access to specific services or for specific population groups. The intention was to use what was learnt from these projects to develop a generic "toolkit" of advice that could be used to inform future projects. A steering group was created to oversee the work. This included representatives of the strategic health authorities (SHAs), hospitals, and primary care trusts (PCTs) in the region, and national bodies including the Health Development Agency and Department of Health Inequalities Unit.

\section{STRATEGIES FOR CHANGE}

An "action research" approach was employed as the intention was that service providers would identify appropriate interventions and implement them themselves, in collaboration with a research team that offered advice and support at every stage of the process. Although this type of activity is not always identified as "action research" and the results are frequently not disseminated beyond the participants, there is now a growing literature to support the use of these methods ${ }^{3}{ }^{4}$ and a developing consensus about the value of appropriate evaluation. ${ }^{5}$ The project was classified as an audit project and ethical approval was not sought.

Health services organisations across the region were invited to nominate specific services which they had identified, whether by audit or other methods, as having potential to improve access for population or patient groups currently poorly served. From these suggestions, eight potential projects with a clear aim of improving access were identified, four related to hospital based services and four related to community or general practice based projects. The research team used visits to the local project teams supplemented by telephone discussions to clarify the nature of the service, the access issues, and the population of concern (table 1). Wide ranging literature searches were undertaken using both databases of published literature (such as Medline and CINAHL), internet search engines (such as Google), and specific relevent website searches (such as the National electronic Library for Health). These identified unpublished reports as well as published literature that could be used to identify potential evidence based interventions that could change access for specific population groups. Where a range of options for intervention were identified, they were presented to local teams to allow them to consider which might be most appropriate to the local setting. All the project teams were invited to a half-day workshop at which they were encouraged to share their plans and commit their organisation to implementing a specific 
Table 1 Proposed projects to reduce inequalities in access to health care in primary and secondary care settings

\begin{tabular}{|c|c|}
\hline Service & Description of action research project \\
\hline $\begin{array}{l}\text { Specialist hospital based services } \\
\text { (1) Sexual health services }\end{array}$ & $\begin{array}{l}\text { Population: asylum seekers and immigrant populations } \\
\text { Evidence of unmet need: local service data suggested relatively low uptake of services by ethnic minority populations } \\
\text { Intervention: to develop appropriate information leaflets about services } \\
\text { Proposed outcome: increased use of services by these patient groups } \\
\text { Progress: established multidisciplinary working group to develop materials }\end{array}$ \\
\hline (2) Termination of pregnancy services & $\begin{array}{l}\text { Population: any pregnant woman requesting referral } \\
\text { Evidence of unmet need: high rates of relatively late termination identified by external audit and anecdotal evidence of } \\
\text { delays in referral pathway } \\
\text { Intervention: to simplify referral pathway allowing direct referral by family planning clinics } \\
\text { Proposed outcome: reduced time from first contact to appointment with service } \\
\text { Progress: developed proposal for revised pathways which was being negotiated with both referring clinicians and } \\
\text { termination service providers }\end{array}$ \\
\hline (3) Services for looked after children & $\begin{array}{l}\text { Population: children in care with drugs and alcohol related problems. } \\
\text { Evidence of unmet need: both local and national data suggesting high level of problems, lack of accessible local } \\
\text { services for young people } \\
\text { Intervention: to create referral pathways to new specialist service } \\
\text { Proposed outcome: appropriate referrals to specialist service } \\
\text { Progress: new service being established, to be located in community venues }\end{array}$ \\
\hline (4) Cardiology appointment system & $\begin{array}{l}\text { Population: patients referred to cardiology outpatients clinic } \\
\text { Evidence of unmet need: local audit showing high proportion of patients either not making an appointment or not } \\
\text { attending when appointment was sent } \\
\text { Intervention: contacting patients not seen in clinic by telephone or visit } \\
\text { Proposed outcome: reduced "did not make appointment" and "did not attend" rates } \\
\text { Progress: attempts to contact patients revealed that patients frequently unavailable at the telephone number or address } \\
\text { available to the service and led to attempts to (1) improve accuracy of contact information and (2) contact patients } \\
\text { sooner after initial referral to explain need to make appointment }\end{array}$ \\
\hline $\begin{array}{l}\text { Community based services } \\
\text { (5) Practice nurse led clinic }\end{array}$ & $\begin{array}{l}\text { Population: people with chronic disease in employment } \\
\text { Evidence of unmet need: local anecdotal evidence that working population less likely to attend clinics in normal } \\
\text { working hours than other age groups } \\
\text { Intervention: Saturday morning clinics } \\
\text { Proposed outcome: increased attendance rates for routine review } \\
\text { Progress: some patients attending for chronic disease management reviews on Saturdays, overall attendance for } \\
\text { reviews increased }\end{array}$ \\
\hline (6) Macmillan drop-in clinic & $\begin{array}{l}\text { Population: patients with cancer and carers in rural areas } \\
\text { Evidence of unmet need: Scottish study suggests cancer services less accessible to rural populations }{ }^{10} \\
\text { Intervention: to increase use of a cancer support drop-in service by directly advertising through local general practices } \\
\text { Proposed outcome: use of service by more patients and from a wider geographical area } \\
\text { Progress: increase in attendance rates from a wider catchment area }\end{array}$ \\
\hline (7) Asthma management in primary care & $\begin{array}{l}\text { Population: patients with asthma not attending routine review } \\
\text { Evidence of unmet need: Hospital Episode Statistics showing high rates of emergency admission for asthma from } \\
\text { many practices serving deprived populations, feedback from practice nurses involved in the local asthma } \\
\text { collaborative that patients they knew to be at higher risk were often the ones not attending for review } \\
\text { Intervention: use of NHS Direct to contact non-attenders and identify patients with poor control } \\
\text { Proposed outcome: to increase routine review and to reduce emergency admissions } \\
\text { Progress: no change in Hospital Episode Statistics for emergency asthma admissions but participating practices report } \\
\text { a higher proportion of their asthma patients undergoing routine review }\end{array}$ \\
\hline (8) COPD management in primary care & $\begin{array}{l}\text { Population: people with COPD } \\
\text { Evidence of unmet need: local survey indicated that practice COPD registers were often absent or inaccurate which } \\
\text { concurred with national evidence that COPD is often undiagnosed or misdiagnosed } \\
\text { Intervention: development of general practice registers for COPD } \\
\text { Proposed outcome: regular routine review for all patients } \\
\text { Progress: COPD coordinator appointed to support practices in developing COPD registers and to ensure the } \\
\text { appropriate use of spirometry for diagnosis and monitoring. Participating practices now have robust mechanisms for } \\
\text { diagnosing and monitoring COPD patients }\end{array}$ \\
\hline
\end{tabular}

intervention to improve access. Progress was reviewed after 3 months at a second half-day workshop in order to identify whether the planned changes had been achieved and what factors appeared to have influenced progress.

\section{RESULTS}

The proposed interventions agreed by service providers, the planned outcomes, and the progress made are described in table 1 . The basis on which projects were identified as having potential to reduce inequalities in access was not necessarily the result of a formal audit. More commonly, as described in table 1 , there were national data suggesting an unmet need for services in specific population groups such as support for rural cancer patients or local audit data suggesting lower uptake of services than expected, as for the cardiology clinic.

The main reason given when suggestions for evidence based interventions were rejected by local teams was a lack of local resources. For example, there is evidence from randomised trials that asthma management can be improved through home visits ${ }^{6}$ or employment of specialist nurses, ${ }^{7}$ but there were not resources available to implement these suggestions. Similarly, the available evidence suggested that 
Box 1 Case study 1: Use of NHS Direct to identify asthma patients who could benefit from clinical review

Problem: Eastern Wakefield primary care trust was concerned by high emergency admission rates for asthma and identified inadequate routine preventive management as a possible cause. A literature review suggested that telephone contact was a potentially effective intervention for patients not attending for routine review.

Intervention implemented: Participating general practices identified patients who had not attended for routine annual review despite an invitation letter. These patients were contacted by NHS Direct nurses who used a symptom assessment instrument to identify individuals with suboptimal control who were then offered an appointment at the practice.

Outcomes: Of 61 patients contacted from one practice, only four were assessed as being well controlled and not requiring review. Of the 57 patients who had been identified as needing to have their management plan reviewed, 51 responded to an invitation and attended the practice.

link workers can improve access to services for asylum seekers $^{8}$ and immigrant communities ${ }^{9}$ but, in the absence of resources for link workers, development of written information about services was seen as the most feasible option.

The progress of projects during the 3 months of follow up varied widely and few managed to collect quantifiable outcomes in this short timescale. Overall progress was greater with the primary care and community projects than with those relating to access to specialist services. The most common reasons for lack of progress were lack of additional resources needed to implement the intervention and the loss of key personnel, whether through retirement or a move to another post. Several complex projects, particularly those which required negotiation with different stakeholder organisations, simply could not be achieved in the short timescale of the programme but some projects developed rapidly. Two of the more successful projects are described in boxes 1 and 2 .

The use of NHS Direct (box 1) was an example of a project based on local audit data which suggested higher hospital admission rates from specific practices which were thought to include "preventable" admissions. This led to audit of attendance for routine review and an intervention that aimed to increase review rates. In contrast, the Macmillan service (box 2) was a service development based on evidence from the rural health literature that suggested that rural cancer patients not only had poorer outcomes related to later presentation but also had more difficulty accessing services. ${ }^{10}$

\section{LESSONS LEARNT}

Despite the relatively well established use of clinical audit to monitor and improve services, it has not proved straightforward to translate equity audit into service changes. A number of lessons were learnt from comparing the experience of successful and unsuccessful projects, and the issues that were identified as most crucial to the success of specific projects to improve access are discussed below.

\section{Availability of evidence for inequalities in access}

Although the overall objective of the project was to tackle inequalities in access, it proved very difficult to quantify inequalities. Moreover, even where baseline information on uptake of services was available, it was not always evident whether variations in uptake were due to inequitable access
Box 2 Case study 2: Promoting the use of drop-in services for cancer patients through general practices and local media

Problem: A specialist nurse running a weekly drop-in service for people with cancer in a rural area was aware that the service was only being used by a minority of the patients who might benefit and that patients were not attending from many of the surrounding areas. The service aimed to reach survivors and the bereaved as well as those currently undergoing cancer treatment.

Intervention implemented: Relevant literature highlighted the need to involve local GPs in development and promotion of the service as primary care staff are well placed to identify individuals who might benefit from the service. Local newspapers and direct contact with local GPs were used to raise awareness of the service.

Outcomes: The heightened awareness of the drop-in centre resulted in increased interest from other health professionals. Two more comparable drop-in services are now being developed. Regular attenders and "one off" visits both increased: current attendance per session is 6-10 patients, 3-6 current carers, and 4 bereaved individuals. The service is now reaching cancer patients who would not previously have received any support, and the main uses of the services cited by clients are information provision and support. Evidence for a widening client base was obtained by documenting the diagnosis and problems of service users when they attended. Patients from the surrounding areas were travelling for up to 30 minutes (and up to 10 miles) to reach the centre.

or difference in underlying need. ${ }^{11}{ }^{12}$ In practice, most of the projects focused on increasing uptake of services. It was assumed that making access easier would reduce inequalities because it would be the population groups who have most difficulty accessing services who would benefit from change. The projects most likely to have a genuine impact on inequalities were those that were not only increasing overall uptake of services-for example, the Macmillan drop-in clinic-but were also targeting populations who had already failed to use a service they were considered to need-for example, attendance for review of asthma management or attendance at a cardiology clinic.

\section{Local leadership and local ownership}

Appropriate leadership is important for managing any service change. It had been assumed that the projects would have support from both managers and from those professionals delivering services, as all projects had been proposed by specific service managers. However, often it was unclear who would be responsible for delivering the project, particularly if the individual who had originally suggested the project had not discussed it with colleagues at the submission stage. In one case the individual who had submitted the project had left the organisation before implementation. It was also apparent that support from senior management was not sufficient if those responsible for delivering change were not convinced it was a priority. Sometimes a clear divergence of views was apparent with some team members not perceiving access as a priority issue or, instead, perceiving the main problem to be high levels of demand rather than inadequate access. It is easy to see that, if a service is perceived as hard pressed and struggling to cope with current levels of demand, it will be difficult to implement a change intended to increase access and service uptake for certain population groups. This 
was an issue for sexual health services which often have long waiting lists. In the case of termination services, concern was expressed by some professionals that, if referral pathways were simplified and obtaining an abortion was seen as "easier", there would be a resultant increase in demand. These specific concerns were addressed by discussing the available evidence that suggests better access to services is not generally associated with increasing demand. ${ }^{13}$

\section{Identification of an appropriate intervention}

Although the research team was concerned with identifying evidence based interventions, the perceived acceptability and feasibility of the intervention in the local setting were the most important factors in determining whether a specific intervention was selected for implementation. The most successful implementation occurred when there was a good match between what the evidence base suggested would be an appropriate type of intervention and what was seen as the most feasible option locally. In every case the evidence was largely from descriptive evaluations of similar services, rarely from randomised controlled trials. The level of evidence, as suggested by conventional grading of evidence, was less important than the description of the setting and service and whether it was directly relevant to the current situation and acceptable to local staff. The ideal evidence base would consist of both robust randomised controlled trial evidence of effectiveness and costs alongside detailed description of a population and setting similar to the local situation. In practice there is frequently a trade-off between using evidence with high internal validity (randomised trials) and external validity (interventions that can be reproduced in the local setting).

\section{Identification of resource implications}

In general, services had no additional resources specifically identified for these service changes and so creativity was required either to make changes within current resources or to identify additional resources. Additional resources were regarded as essential for some interventions-for example, where telephone follow up was identified as a potentially effective way of contacting people with asthma who could benefit from review but did not turn up for routine appointments, ${ }^{14}$ or for the cardiology clinic to contact patients who did not make appointments. The former project identified an opportunity to use the spare capacity of the NHS Direct service to contact asthma patients. Other projects involved the redeployment of existing resources-for example, using Saturday clinics in general practice to review chronic disease management when these clinics were already being held to see patients with urgent problems.

\section{CONCLUSIONS}

Overall interventions to improve access must be sensitive to local settings and are unlikely to succeed without both practical and managerial support. Key elements for successful interventions appear to include local leadership, identification of an intervention which is both evidence based and locally practicable, and identification of additional resources to support increased activity.
Using experience from these pilot projects, a "toolkit" document describing the issues to be considered at each stage in the change management process has been developed to disseminate what was learnt from the project to help future access initiatives. This is being shared with both "front line" clinicians and with those responsible for commissioning and developing services. It is also being used to generate discussion of how the equity audit cycle can be harnessed to address inequity in service provision. The toolkit and supporting documentation can be accessed from the project website. ${ }^{15}$

\section{ACKNOWLEDGEMENTS}

The eight volunteer service providers all contributed to the development of both their own projects and the resultant toolkit.

\section{Authors' affiliations}

E C Goyder, L Blank, E Ellis, A Furber, J Peters, ScHARR, University of Sheffield, Sheffield, UK

K Sartain, Scarborough, Whitby and Ryedale Primary Care Trust, UK C Massey, West Yorkshire Strategic Health Authority, UK

This project was funded by the Regional Public Health Group (Yorkshire and Humber) and supported by the Yorkshire and Humber Inequalities in Access to Services Group.

The authors have no competing interests.

\section{REFERENCES}

1 Hart JT. The inverse care law. Lancet, 1971;405-12.

2 Department of Health. Health equity audit: a guide for the NHS. London: Department of Health, 2003, http://www.dh.gov.uk/assetRoot/04/08/41/ 39/04084139.pdf (accessed 21 November 2004).

3 Waterman $H$, Tillen D, Dickson R, et al. Action research: a systematic review and guidance for assessment. Health Technol Assess 2001;5:1-157 (available from www.ncchta.org).

4 Hampshire A, Blair M, Crown N, et al. Action research: a useful method of promoting change in primary care? Fam Pract 1999;16:305-11.

5 Harvey G, Wensing M. Methods for evaluation of small scale quality improvement projects. Qual Saf Health Care, 2003;12, 210-4.

6 Hughes DDH, McLeod M, Garner B, et al. Controlled trial of a home and ambulatory program for asthmatic children. Pediatrics 1991;87:54-61.

7 Moudgil H, Marshall T, Honeybourne D. Asthma education and quality of life in the community: a randomised controlled study to evaluate the impact on white European and Indian subcontinent ethnic groups from socioeconomically deprived areas in Birmingham, UK. Thorax 2000;55:177-83

8 Hounslow Primary Care Trust (PCT). Primary care services for refugees and asylum seekers: a review. Hounslow PCT, 2004.

9 Bell TS, Branston LK, Newcombe RG, et al. Interventions to improve uptake of breast screening in inner city Cardiff general practices with ethnic minority lists. Ethnicity Health 1999;4:277-84.

10 Bain NSC, Campbell NC. Treating patients with colorectal cancer in rural and urban areas: a qualitative study of the patients' perspective. Fam Pract 2000;17:475-9.

11 Goddard M, Smith P. Equity of access to health care. York: Centre for Health Economics, University of York, 1998.

12 Gulliford M, Hughes D, Figeroa-Munoz J, et al. Access to health care. Report of a Scoping Exercise for the National Coordinating Centre for NHS Service Delivery and Organisation R\&D, London, 2001.

13 David HP, Morgall JM, Osler M, et al. United States and Denmark: different approaches to health care and family planning. Stud Fam Plann 1990;21:1-19.

14 Pinnock H, Bawden R, Proctor S, et al. Accessibility, acceptability, and effectiveness in primary care of routine telephone review of asthma: pragmatic, randomised controlled trial. BMJ 2003;326:477.

15 Peters J, Goyder I, Blank L, et al. Toolkit to address inequalities in access to care. Sheffield: ScHARR, 2004, http://www.shef.ac.uk/scharr/sections/ph/ research/h_i/toolkit.html (accessed 4 January 2005). 